\title{
THE QUALITY OF LIFE IN PATIENTS WITH TOTAL LARYNGECTOMY
}

\author{
Raluca GRIGORE ${ }^{1,2}$, Alina L. A. OANCEA ${ }^{1,2} \bowtie$, Catrinel SIMION-ANTONIE ${ }^{1}$, \\ Bogdan POPESCU ${ }^{1,2}$, Liliana NITU ${ }^{1,2}$, Paula BEJENARU ${ }^{1}$, Gloria MUNTEANU ${ }^{1}$, \\ Anca CIRSTEA ${ }^{1}$, Mihnea CONDEESCU ${ }^{1,2}$, Luiza SIRETEANU ${ }^{1}$, Amer OTHMAN ${ }^{1}$, \\ Bianca TAHER ${ }^{1}$, Simona RUJAN ${ }^{1}$, Ruxandra NEDELCU ${ }^{1}$, Teodora DIACONU ${ }^{1}$, \\ Denisa MITRAN ${ }^{1}$, Elena ARJOCA ${ }^{1}$, Teodora POPA ${ }^{1}$, Claudiu CURCA ${ }^{1}$, Roxana ANDRONE${ }^{1}$, \\ Alisa DIMCEA ${ }^{1}$, Alexandru NICOLAESCU ${ }^{2}$, Serban V.G. BERTESTEANU ${ }^{1,2}$ \\ ${ }^{1}$ Coltea Clinical Hospital, ENT \& Head and Neck Surgery Department, Bucharest, Romania \\ 2 "Carol Davila" University of Medicine and Pharmacy, Bucharest, Romania
}

\section{Abstract}

Introduction. The quality of life of patients after total laryngectomy is influenced by both the disease and the radical therapeutic interventions. After surgical treatment, vocal rehabilitation, along with pulmonary and deglutition rehabilitation, are necessary.

The objective of the study was to assess the quality of life in patients with total laryngectomy.

Materials and methods. A questionnaire with 14 questions was randomly addressed to 100 patients with total laryngectomy who presented to Coltea Clinical Hospital, Bucharest, Romania, over a period of three months.

Results. Fifty patients answered that they had no pain. Regarding everyday activities, 34 patients answered that they were as active as before surgery. Regarding their appearance, 50 patients answered that there is no change, or the change is minor, while 39 answered that their appearance bothers them, but they remain active, and 5 answered that they feel disfigured and limit their activity, while 6 patients answered that they cannot be with other people because of their

\section{RÉSUMÉ}

La qualité de vie des patients avec laryngectomie totale

Introduction. La qualité de vie des patients après une laryngectomie totale est influencée à la fois par la maladie et par les interventions thérapeutiques radicales. Après un traitement chirurgical, une rééducation vocale, ainsi qu'une rééducation pulmonaire et de déglutition, sont nécessaires.

L'objectif de l'étude était d'évaluer la qualité de vie des patients atteints de laryngectomie totale.

Matériaux et méthodes. Un questionnaire de 14 questions a été adressé au hasard à 100 patients atteints de laryngectomie totale qui se sont présentés à l'hôpital clinique Coltea, Bucarest, Roumanie, sur une période de trois mois.

Résultats. Cinquante patients ont répondu qu'ils n'avaient aucune douleur. Concernant les activités quotidiennes, 34 patients ont répondu qu'ils étaient aussi actifs qu'avant la chirurgie. Concernant leur apparence, 50 patients ont répondu qu'il n'y a pas de 
aspect. 34 patients answered that they could swallow as well as prior to surgery, other 34 patients answered that they cannot swallow certain foods, while 21 answered that they only swallow liquid food or are dependent on a feeding tube. Regarding everyday activity, 67 patients answered there are times when they cannot keep up with their old pace, but they get out of the house and enjoy life. About their mood, 38 patients answered that they were not in a good mood, nor depressed, while 36 said their mood is generally good and only occasionally affected by cancer. Six patients answered that their mood is excellent, while $15 \mathrm{pa}$ tients were somewhat depressed and 5 were extremely depressed.

Conclusions. The quality of life is influenced by the patients' appearance after total laryngectomy, and their ability to maintain everyday activities. Swallowing, taste and saliva quality have a great impact on the quality of life of patients with total laryngectomy and also influence their nutritional status.

Keywords: quality of life, total laryngectomy, voice rehabilitation. changement, ou le changement est mineur, tandis que 39 ont répondu que leur apparence les dérange, mais ils restent actifs, et 5 ont répondu qu'ils se sentaient défigurés et limitaient leur activité, tandis que 6 patients ont répondu qu'ils ne peuvent pas être avec d'autres personnes à cause de leur aspect. 34 patients ont répondu qu'ils pouvaient avaler aussi bien qu'avant la chirurgie, 34 autres patients ont répondu qu'ils ne pouvaient pas avaler certains aliments, tandis que 21 ont répondu qu'ils avalaient uniquement des aliments liquides ou dépendaient d'une sonde d'alimentation. En ce qui concerne l'activité quotidienne, 67 patients ont répondu qu'il y a des moments où ils ne peuvent pas suivre leur ancien rythme, mais ils sortent de la maison et profitent de la vie. Au sujet de leur humeur, 38 patients ont répondu qu'ils n'étaient pas de bonne humeur, ni déprimés, tandis que 36 ont déclaré que leur humeur était généralement bonne et seulement occasionnellement affectée par le cancer. Six patients ont répondu que leur humeur était excellente, tandis que 15 patients étaient un peu déprimés et 5 étaient extrêmement déprimés.

Conclusions. La qualité de vie est influencée par l'apparence des patients après une laryngectomie totale et leur capacité à poursuivre leurs activités quotidiennes. La déglutition, le goût et la qualité de la salive ont un grand impact sur la qualité de vie des patients atteints de laryngectomie totale et influencent également leur état nutritionnel.

Mots-clés: qualité de vie, laryngectomie totale, réhabilitation vocale.

the radical therapeutic interventions. The main entities in assessing patients with locally advanced laryngeal cancer are the quality of life and the health status. After the surgical treatment, vocal rehabilitation, along with pulmonary and deglutition rehabilitation, are necessary. Also, psychotherapy and counselling are key parts of the treatment ${ }^{3,4}$.

Unlike patients diagnosed with other types of carcinoma, patients with laryngeal cancer are often unable to fulfil their basic needs. Dedicated physicians, nurses and therapists must work with these patients and help them in the recovery $y^{5.7}$.

The obJective OF THE STUdY was to assess the quality of life in patients with total laryngectomy.

\section{Materials AND Methods}

In order to assess the quality of life and health status in patients with total laryngectomy, a questionnaire with 14 questions was randomly addressed to 
patients who presented to Coltea Clinical Hospital, Bucharest, Romania, for follow up over a period of three months. The inclusion criteria were patients who have underwent total laryngectomy, at least one month after surgery. We excluded from the study the patients with neurological disabilities or any other severe pathologies, not related to laryngeal carcinoma, that affected their understanding. Patients with any other severe pathologies that may affect their quality of life were also excluded from the study.

The study included 100 patients, both patients who benefit from voice rehabilitation and patients who did not benefit from this procedure. We assessed the ability to communicate, swallow, anxiety or depression and health status. All patients have given their written consent and the questionnaire was approved by the Ethics Commitee ${ }^{7}$. All the patients included in the study had radiotherapy and 30\% received chemotherapy as well.

The questionnaire assessed the ability to communicate, swallow, depression and anxiety and their current health status. All patients had completed the questionnaire themselves. We used Microsoft Excel to collect and process the data.

\section{Results}

Regarding pain, 50 patients answered that they felt no pain, while 34 answered they have mild pain that does not need medication. Only 10 patients had moderate pain that requires regular medication and 6 patients complaint of severe pain controlled only by prescription pills ${ }^{2}$ (Figure 1).
Regarding everyday activities, 34 patients answered that they were as active as before surgery, 28 answered that there are moments when they can't keep up as before, other 28 patients complained of feeling often tired but still get out of the house every day, while only 10 answered that they spend most of the time inside (Figure 2).

Regarding their appearance, the results were surprising, 50 patients answered that there is no change, or the change is minor, while 39 answered that their appearance bothers them, but they remain active and 5 answered that they feel disfigured and limit their activity, while 6 patients answered that they cannot be with other people because of their aspect.

In western countries, associations of laryngectomees have developed necklaces and other accessories for the trach tube in order to improve their aspect (Figure 3).

Most patients with head and neck malignancies are underweight or even cachectic, especially those in advanced stages. Nutritional assessment is very important in any oncological patient, as they need special nutritional support. Their ability to swallow and to taste food must be evaluated. In our study, 34 patients answered that they could swallow as well as before surgery, other 34 patients answered that they cannot swallow certain foods, while 21 answered that they only swallow liquid food or are dependent on a feeding tube. This was directly related to the size of the tumour and how large the pharyngeal resection is necessary in order to have negative margins (Figure 4).

Regarding mastication, 50 patients could eat soft food, but not solid food, while 34 could chew as well

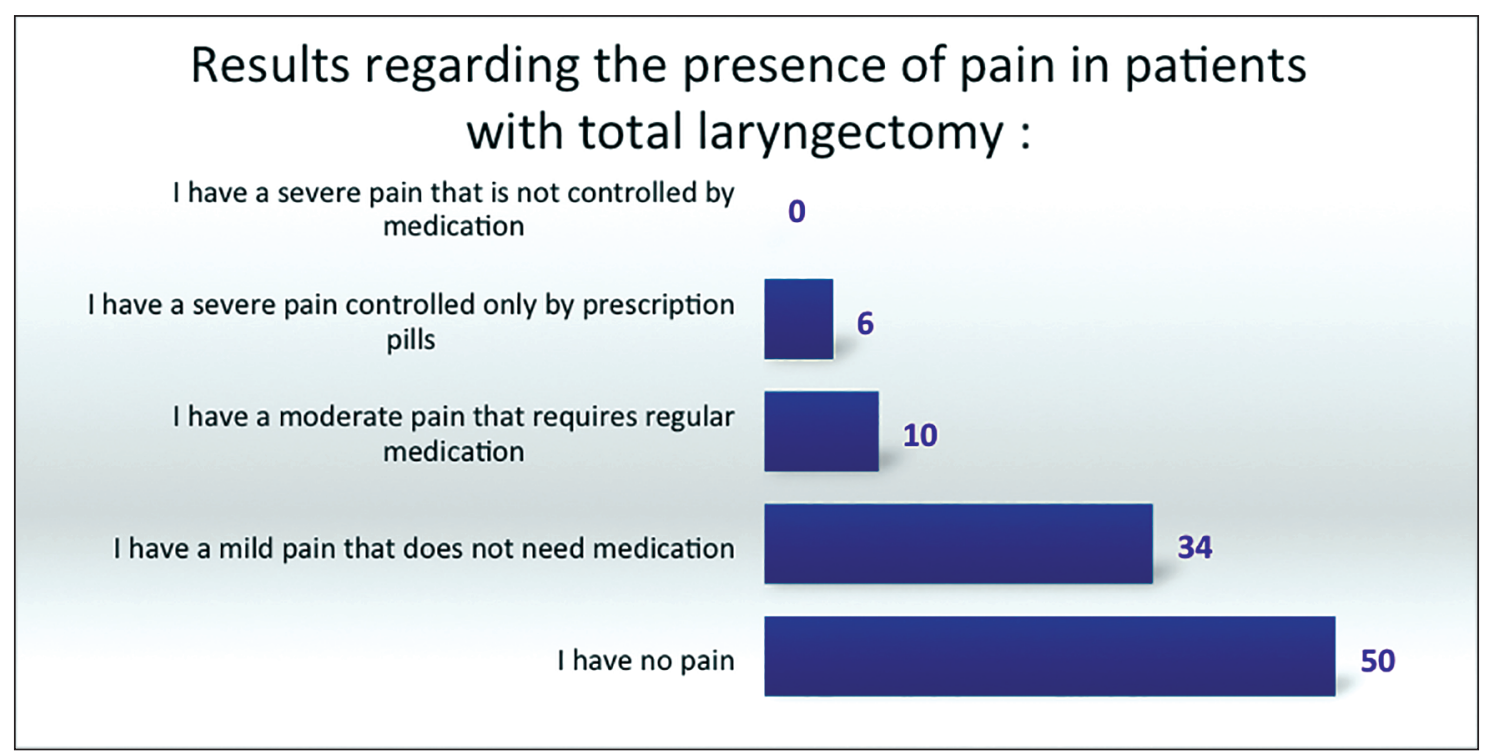

Figure 1. Results regarding the presence of pain in patients with total laryngectomy. 


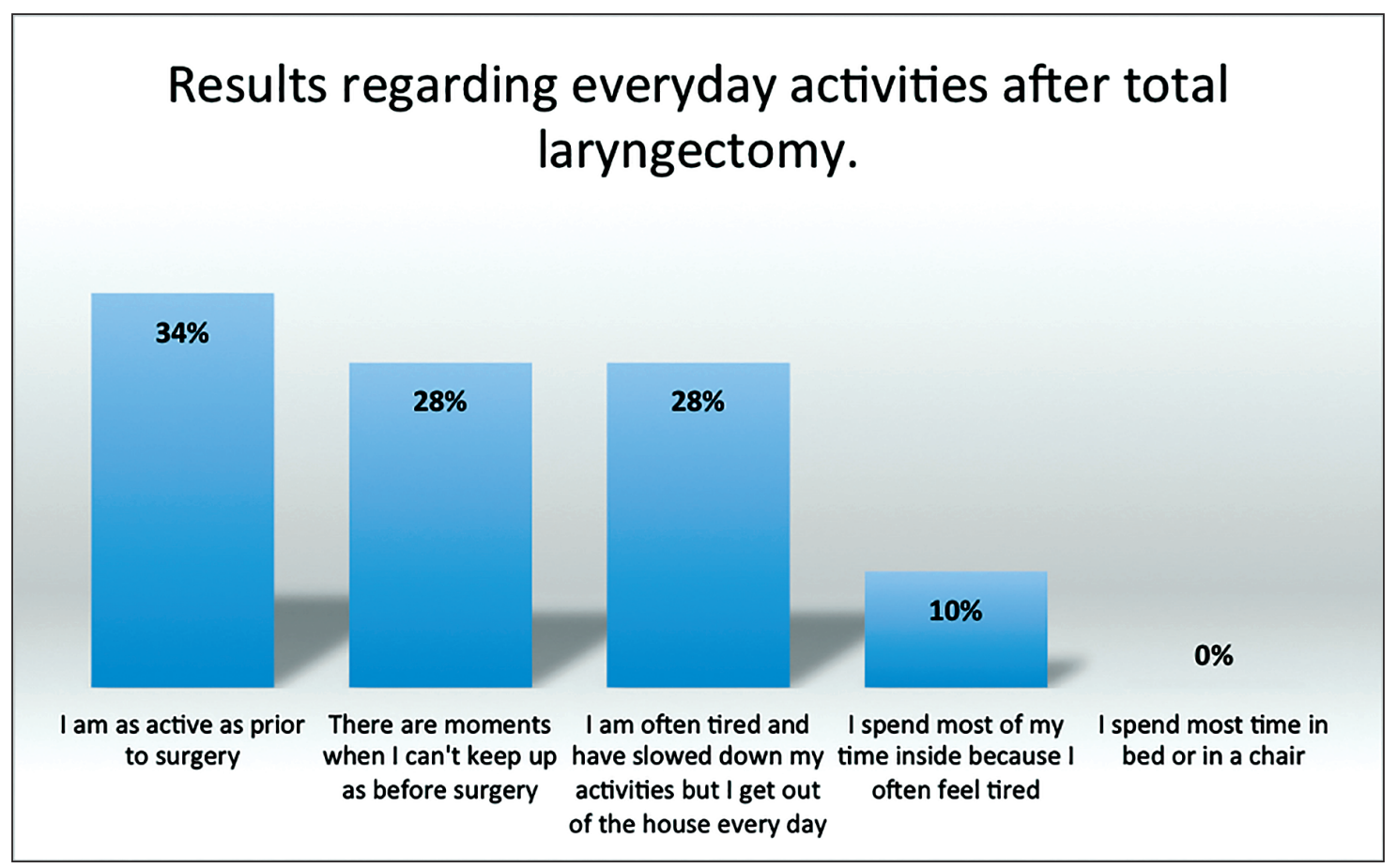

Figure 2. Results regarding everyday activities after total laryngectomy.

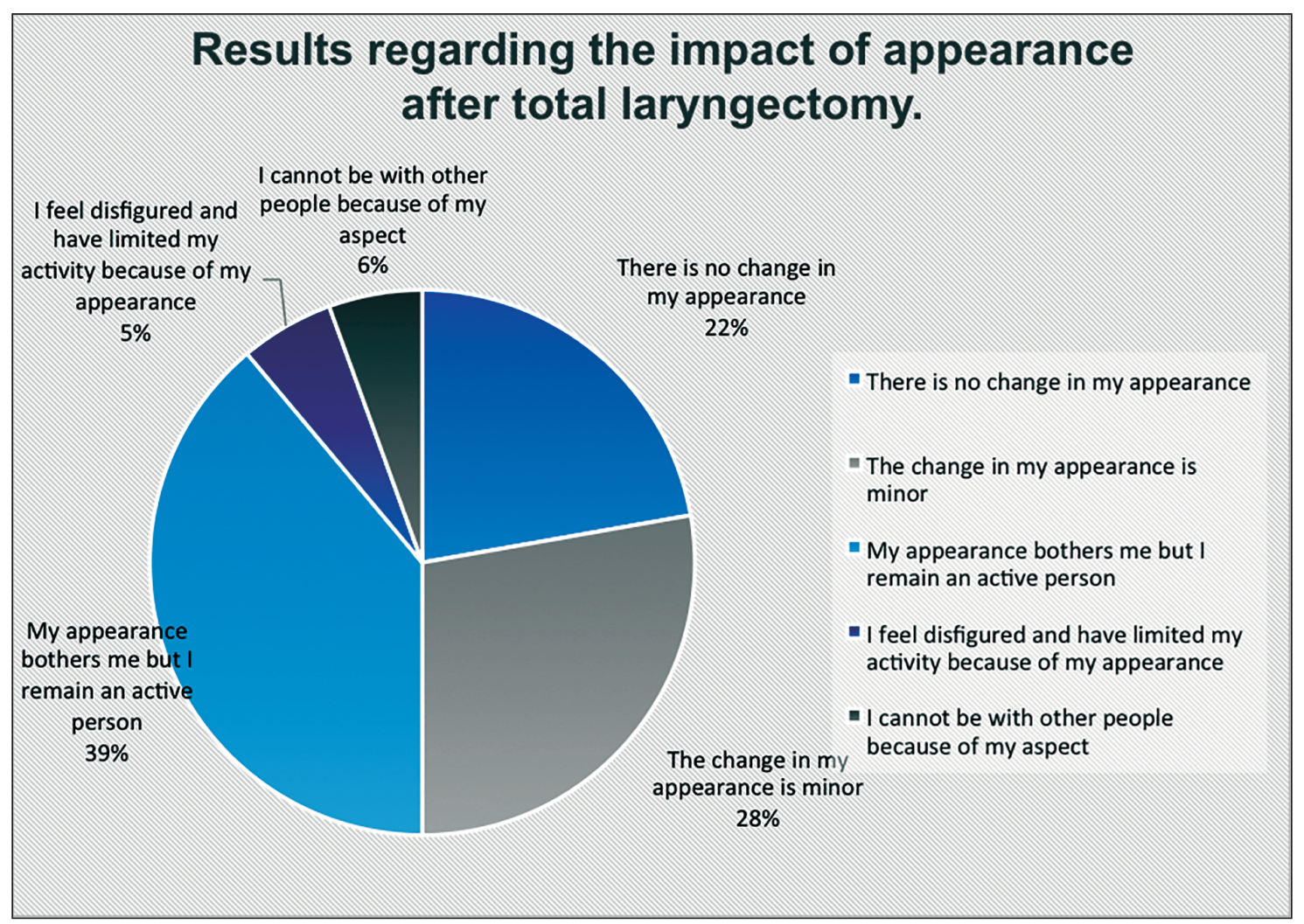

Figure 3. Results regarding the impact of appearance after total laryngectomy.

as before surgery. 16 could not even chew soft foods (Figure 5).

Speech is a very important aspect for patients with laryngeal cancer, so doing voice rehabilitation per primam, in the same time with total laryngectomy, represents the gold standard in the surgical treatment of advanced laryngeal carcinoma. In this study, 50 patients could speak with a voice prosthesis, 


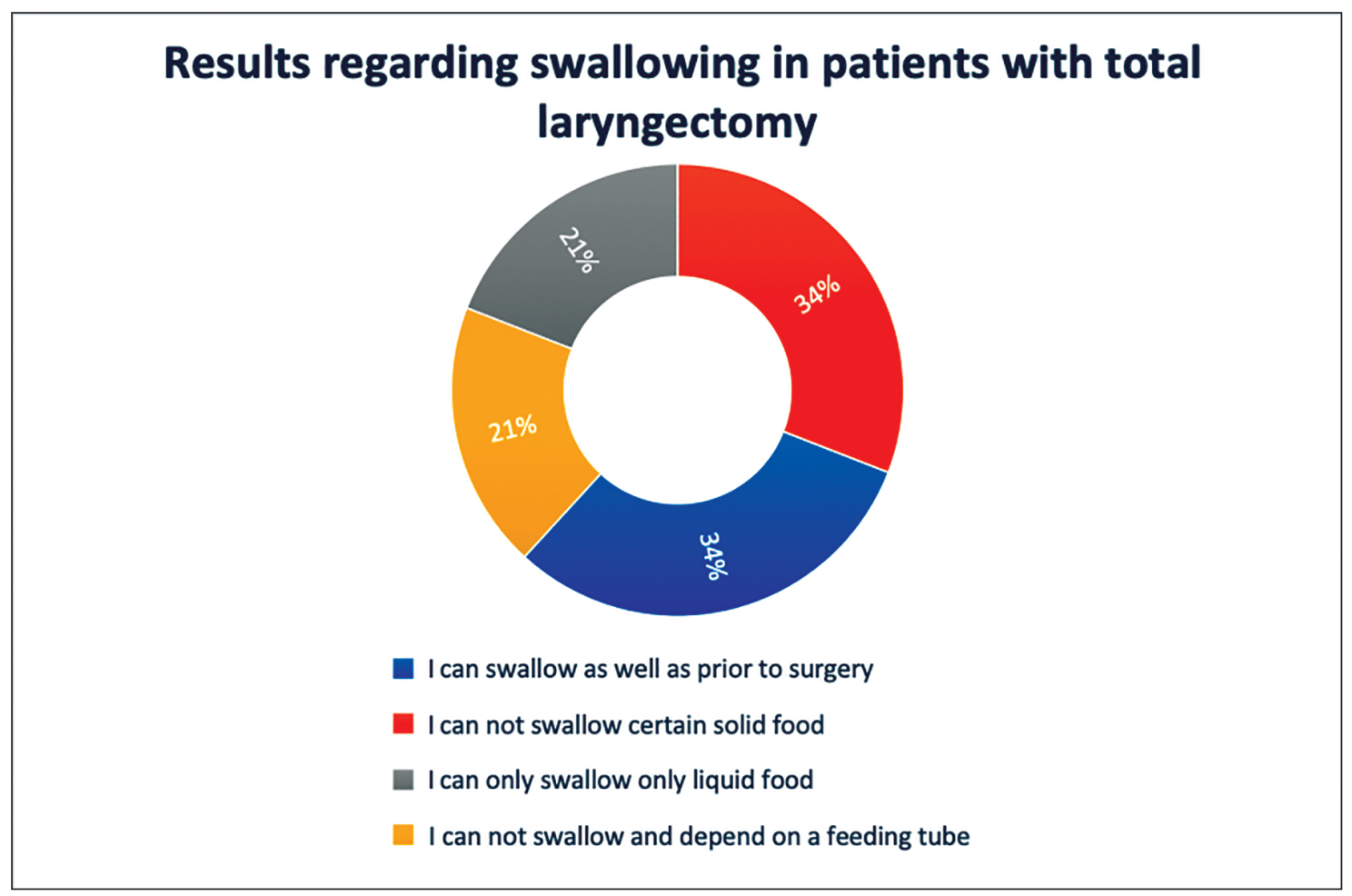

Figure 4. Results regarding swallowing in patients with total laryngectomy.

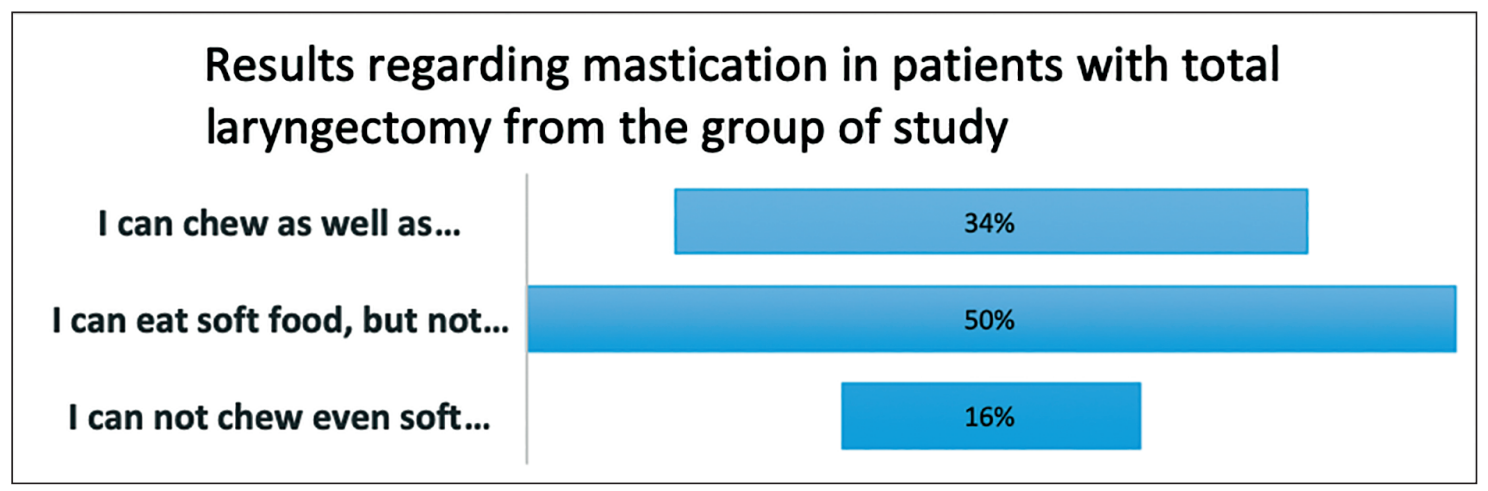

Figure 5. Results regarding mastication in patients with total laryngectomy from the group of study.

10 by using the oesophageal voice and 5 patients with the help of a laryngophone. 20 patients answered that they could not make any sounds, but their family usually understands what they are trying to say, while 15 patients could not speak and have a hard time making themselves understood (Figure 6).

Regarding smell, most patients have a lack of smell or don't usually sense smell, this emphasizing once more the need for specialised therapy of olfactory rehabilitation and the need to make these methods known to the entire ENT community. 35 patients answered that they never sense smells, 38 answered that they don't usually sense smells, 22 can smell intense scents and only 5 patients answered that their smell is the same as before surgery ${ }^{7}$ (Figure 7).

Taste is very important in assessing the quality of life and maintaining an optimal nutritional status. In our study, 50 patients could taste food or most foods normally, while 30 patients answered that they could taste some foods and 20 could not taste any food $^{2}$ (Figure 8).

From the 100 patients, 61 patients answered the question regarding their saliva which is of normal consistency and 25 answered that they have less saliva but it's enough. Only 10 patients answered they have too little saliva, while 4 answered that they have no 


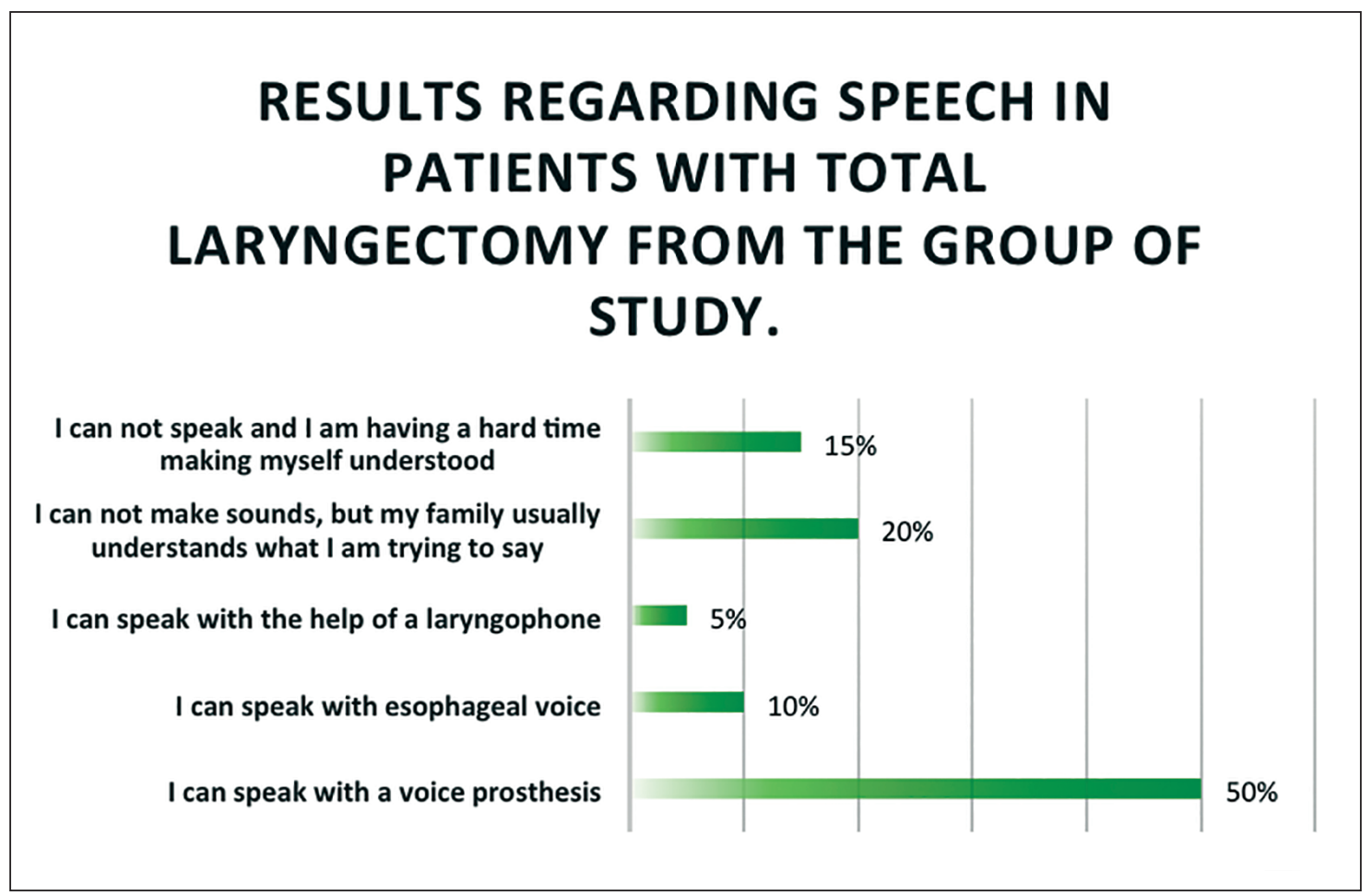

Figure 6. Results regarding speech in patients with total laryngectomy from the group of study.

\section{THE RESULTS REGARDING SMELL IN PATIENTS WITH TOTAL LARYNGECTOMY FROM THE GROUP OF STUDY}

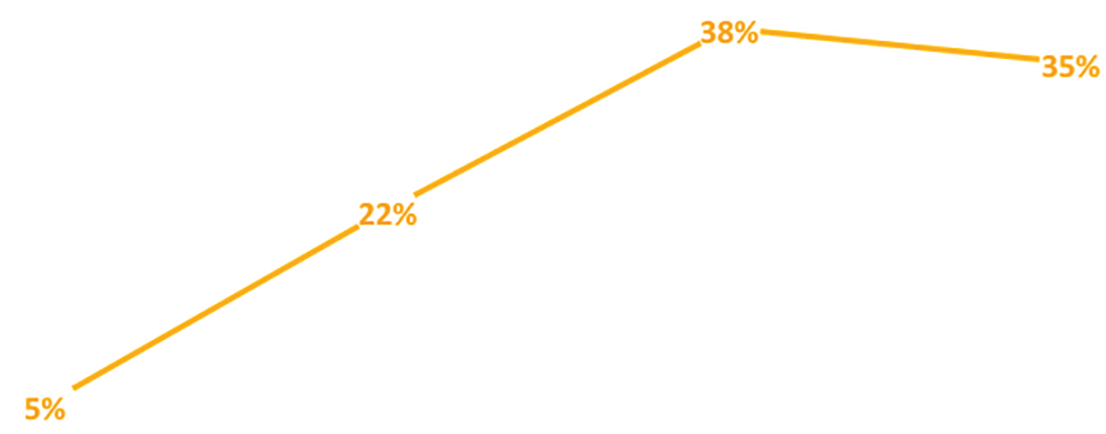

My smell is the same I can smell intense I don't usually sense I never sense smells as prior to surgery scents smells

Figure 7. Results regarding smell in patients with total laryngectomy from the group of study. 


\section{RESULTS REGARDING THE SENSE OF TASTE AFTER TOTAL LARYNGECTOMY.}

I can taste food normally

I can taste most foods normally

I can taste some foods

I can not taste any food

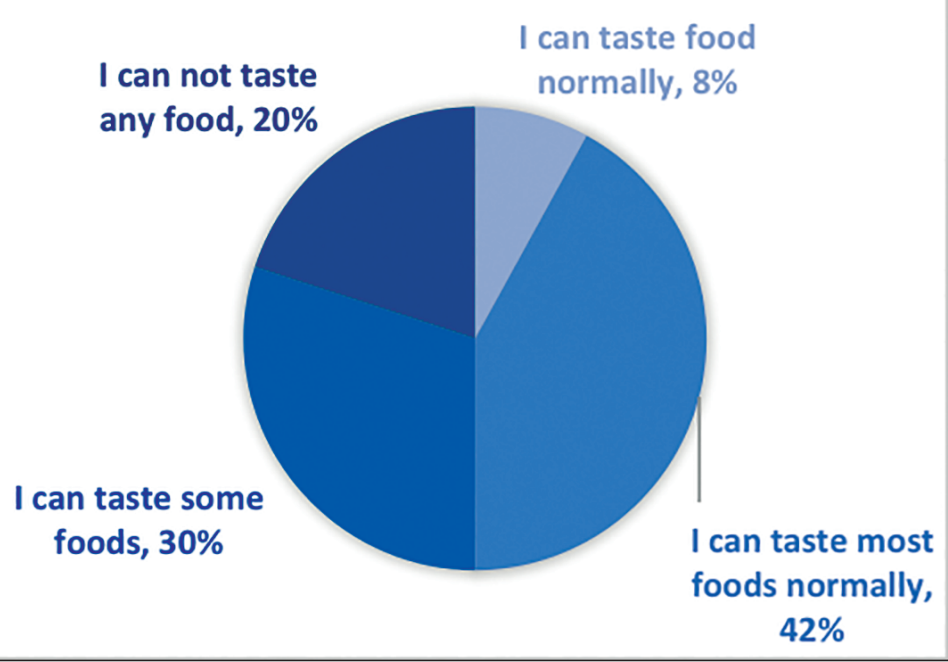

Figure 8. Results regarding the sense of taste after total laryngectomy.

\section{The quality of saliva in patients with laryngeal carcinoma who benefit from surgery and radiotherapy in the group of study}
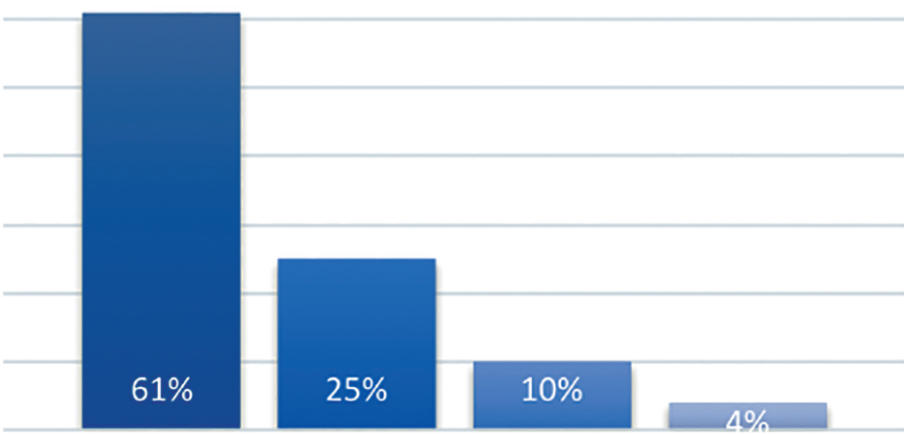

have too little saliva

I have no saliva

1

Figure 9. The quality of saliva in patients with laryngeal carcinoma who benefit from surgery and radiotherapy.

saliva. This is a common side effect of radiotherapy (Figure 9).

Regarding activity, 67 patients answered there are times when they cannot keep up with their old pace, but they get out of the house and enjoy life.
This is a satisfying response, as we aim for a good quality of life for these patients, even after extensive surgery for laryngeal cancer. Eleven patients answered that they were as active as ever, while 16 said there are many things they wish they could do but 


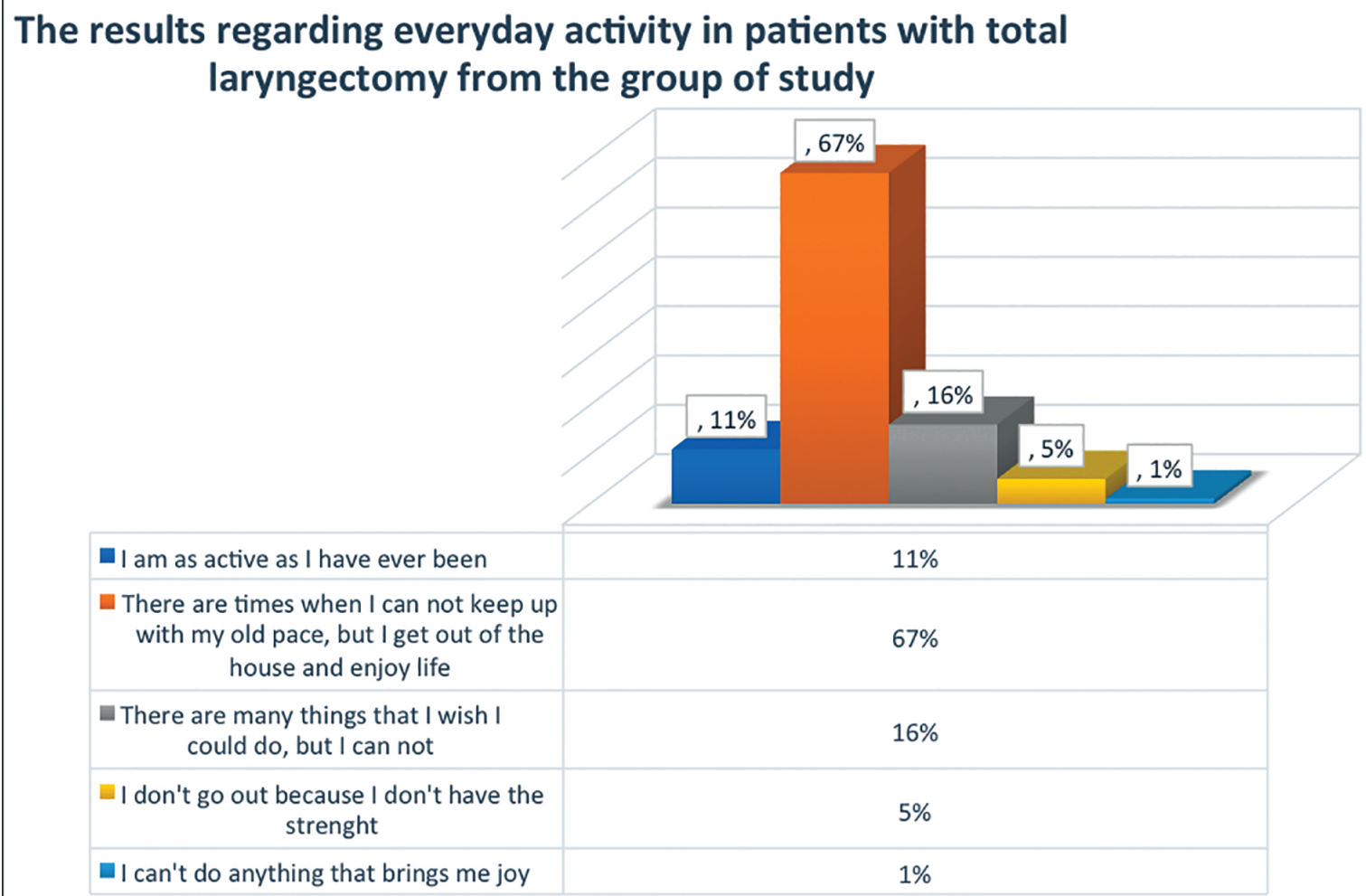

Figure 10. Results regarding everyday activity in patients with total laryngectomy from the group of study.

\section{THE PRESENCE OF ANY DISCOMFORT REGARDING THE SHOULDER AFTER TOTAL LARYNGECTOMY AND NECK DISSECTION IN PATIENTS FROM THE GROUP OF STUDY, WITH ADVANCED DISEASE.}

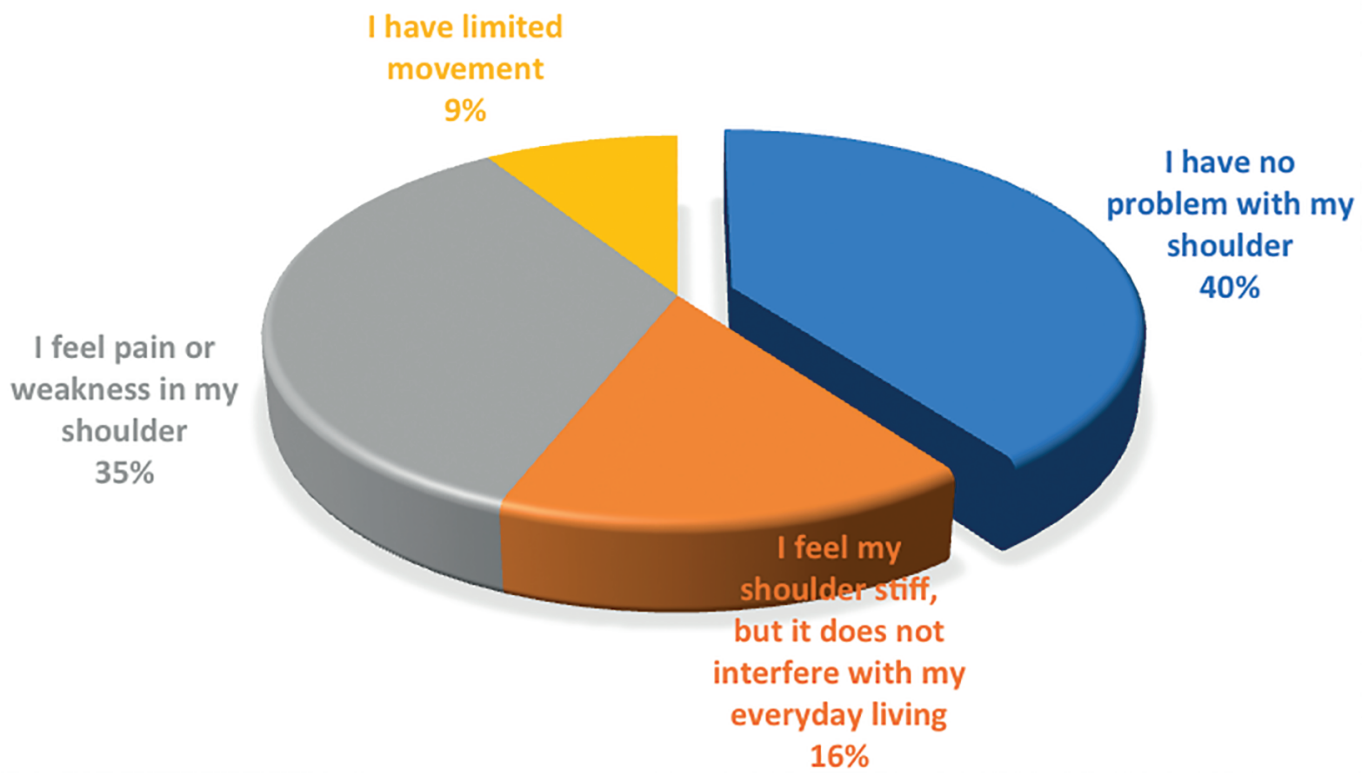

Figure 11. The presence of any discomfort regarding the shoulder after total laryngectomy and neck dissection in patients from the group of study, with advanced disease. 


\title{
Results regarding the mood of patients with total laryngectomy from the group study
}

\author{
I am extremly depressed \\ I am somewhat depressed because of the disease \\ I am neither in a good mood, nor depressed \\ My mood is generally good and only ocasionally \\ affected by cancer \\ My mood is excellent and not affected by cancer
}

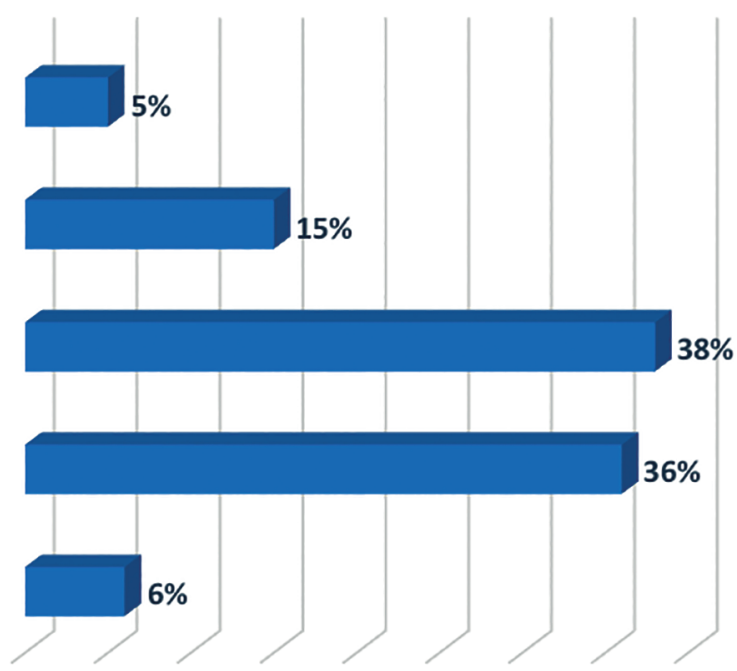

Figure 12. Results regarding the mood of patients with total laryngectomy from the group study.

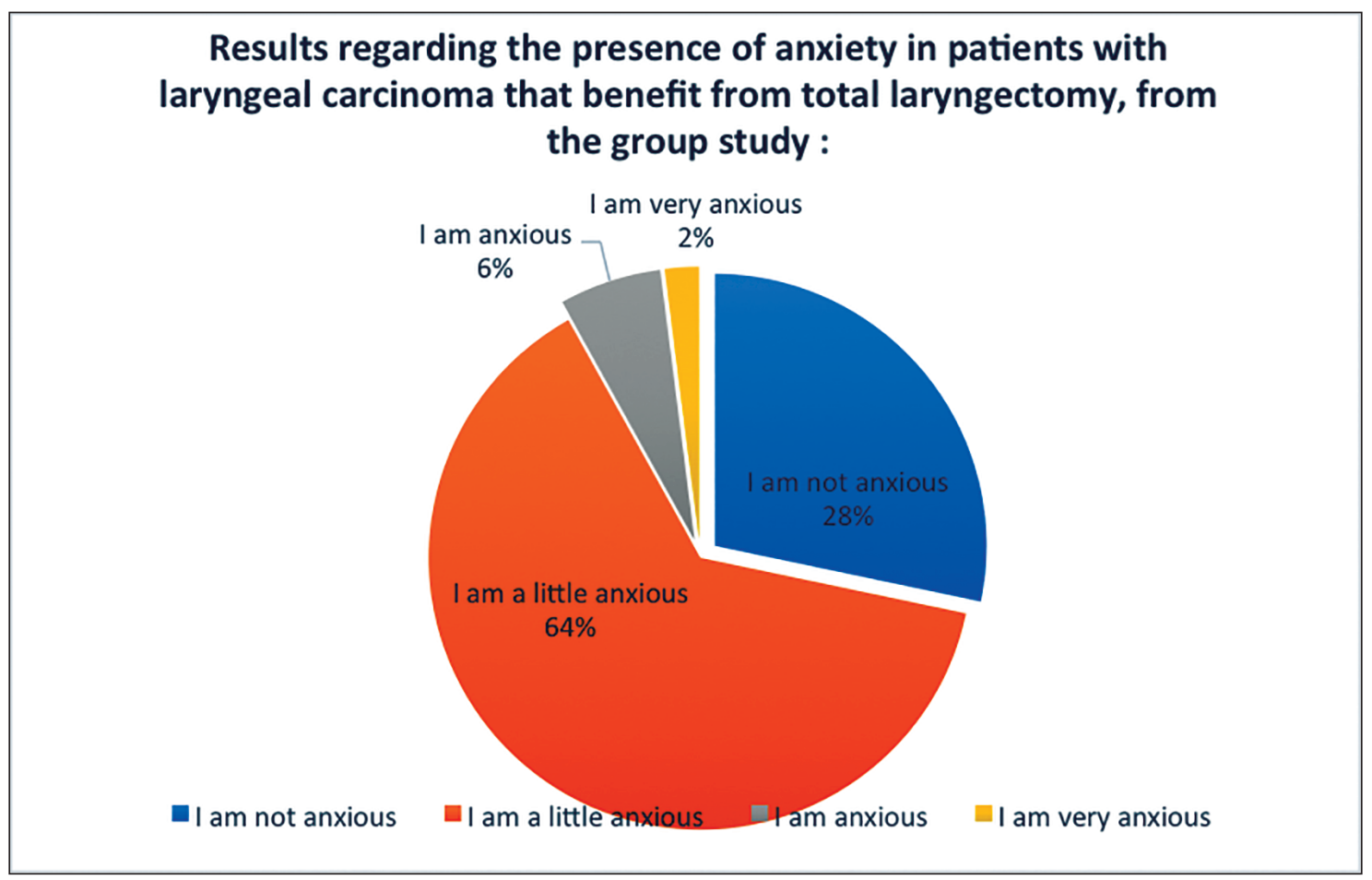

Figure 13. Results regarding the presence of anxiety in patients with laryngeal carcinoma who benefit from total laryngectomy, from the group study.

cannot, 5 patients answered that they don't go out because they don't have the strength and one patient answered that he cannot do anything that brings him joy (Figure 10) .
Regarding the pain felt in the shoulder after surgery, 40 patients answered that they had no problem with their shoulder, 35 complained about weakness or pain, 16 felt their shoulder stiff and 9 had limited 
movements. All these patients had advanced disease with metastatic lymph nodes (Figure 11).

About their mood, most of them (38 patients) answered that they were not in a good mood, nor depressed, while 36 said their mood is generally good and only occasionally affected by cancer. 6 patients answered that their mood is excellent while $15 \mathrm{pa}$ tients were somewhat depressed and 5 were extremely depressed. It is important to stress the importance of psychotherapy and specialized counselling, as important parts of the oncological treatment and the need to be helped by the government.

About their anxiety, most of them admitted of being a little anxious (64 patients), while 28 patients answered that they are not anxious. 6 were anxious and 2 very anxious (Figure 12,13).

\section{Discussion}

Total laryngectomy represents a radical surgery, necessary in advanced laryngeal malignancies, with a great impact over the quality of life. The treatment of patients with laryngeal cancer is complex, a multidisciplinary team is necessary, formed by the head and neck surgeon, oncologist, anaesthesiologist, speech therapist, pulmonary and olfactometry rehabilitation therapist, psychiatrist, kinesitherapist and also nutrition assessment and pain team ${ }^{8-11}$.

In this study, we addressed the main concerns that may influence the quality of life for these patients, including voice, smell and deglutition. Comparing the results with the published literature, the outcome was similar, voice rehabilitation and the ability to communicate had a positive influence over the quality of life for the total laryngectomee ${ }^{12-14}$.

Swallowing-related quality of life is influenced by the support given to these patients by trained personnel in deglutition rehabilitation ${ }^{6,7,15,16}$.

The main limit of this study is represented by the number of patients involved and that it assesses one moment in the patient's evolution. In the future, the questionnaire will be addressed again in order to evaluate the quality of life over time for patients with total laryngectomy.

There is a great need for specialised medical personnel, physicians, nurses and therapists to help the patient with total laryngectomy gain a good quality of life $\mathrm{e}^{12,14,17}$. This is useful for their physical and mental status, but the health education of communities is also important, in order to make the social reintegration of these patients possible. The cost and burden for this kind of care are high, but necessary $y^{4,5,18,19}$.

\section{Conclusions}

The radical treatment necessary for patients with advanced laryngeal carcinoma represents a great burden for the patient, affecting their quality of life $\mathrm{f}^{16,20}$. The quality of life is influenced by the patients' appearance after total laryngectomy, and their ability to maintain their everyday activities ${ }^{21,22}$.

Swallowing, taste and saliva quality have a great impact over the quality of life of patients with total laryngectomy and also influence their nutritional status $^{23-25}$. The ability to speak is one of the main concerns of the patient with laryngeal cancer and per primam voice rehabilitation represents the gold standard of treatment in any western country.

\section{Author contributions}

R.G., A.L.A.O., B.P., L. N., A.N. and S.V.G.B. were responsible for the diagnostic procedures, clinical diagnosis and treatment decisions. C.S.A., P.B., G.M., A.C., M.C., L.S., A.O., B.T., S.R., R.N., T.D., D.M., E.A., T.P., C.C., R.A. and A.D. wrote the manuscript. All authors have read and agreed to the published version of the manuscript.

\section{Compliance with Ethics Requirements:}

„The authors declare no conflict of interest regarding this article"

"The authors declare that all the procedures and experiments of this study respect the ethical standards in the Helsinki Declaration of 1975, as revised in 2008(5), as well as the national law. Informed consent was obtained from all the patients included in the study"

„No funding for this research"

\section{Acknowledgements: none}

\section{References}

1. https://www.who.int. (Accessed on November 23, 2019).

2. Stanca H, Petrović Z, Munteanu M. Transluminal Nd: YAG laser embolysis - a reasonable method to reperfuse occluded branch retinal arteries. Vojnosanitetski Pregled. 2014;71(11):1072-1077.

3. Stanca H, Suvac E, Munteanu M, et al. Giant cell arteritis with arteritic anterior ischemic optic neuropathy. Romanian Journal of Morphology and Embryology. 2017;58(1):281-285.

4. Munteanu M, Rosca C, Stanca H. Sub-inner limiting membrane hemorrhage in a patient with Terson syndrome. International Ophthalmology. 2019;39(2):461-464.

5. Stanca H, Munteanu M, Jianu D, et al. Femtosecond-LASIK outcome using the VisuMax-Mel 80 platform for mixed astigmatism refractive surgery. Romanian Journal of Morphology and Embryology. 2018;59(1):277-283.

6. Balica N, Poenaru M, Doros C, et al. The management of the oropharyngeal anterior wall cancer. Romanian Journal of Morphology and Embryology. 2018;59(1):113-119. 
7. Grigore R, Bertesteanu S, Simion-Antonie C, et al. Quality of life and health status of patients after total laryngectomy. Romanian Journal of ENT and Head and Neck Society. 2019; $3(2): 10-13$

8. Ciuhu AN, Rahnea Nita RA, Popescu M, et al Evidence of strong opioid therapy for palliation of breathlesness in cancer patients. Farmacia. 2017;65(2):173-178.

9. Tiglis M, Neagu TP, Elfara M, et al. Nefopam and its role in modulating acute and chronic pain. Rev Chim (Bucharest). 2018;69(10):2877-2880.

10. Dumitru N, Cocolos A, Caragheorgheopol A, et al. Collagen - the ultrastructural element of the bone matrix. Rev Chim (Bucharest). 2018;69(7):1706-1709.

11. Diaconu C, Balaceanu A, Ghinescu M. A neck mass that disapears at compression: is it a reason for concern? Acta Medica Mediterranea. 2015;31(2):339-341.

12. van Sluis K, Kornman A, van der Molen L, van den Brekel M, Yaron G. Women's perspective on life after total laryngectomy: a qualitative study. International Journal of Language $\mathcal{B}$ Communication Disorders. 2019;1(1):1-12.

13. Allegra E, La Mantia I, Bianco M, et al. Verbal performance of total laryngectomized patients rehabilitated with esophageal speech and tracheoesophageal speech: impacts on patients' quality of life. Psychology Research and Behavior Management. 2019;12(1):675-681.

14. Yang $\mathrm{H}$, Han D, Ren X, Luo H, Li X. Investigation of swallowing function and swallowing-related quality of life after partial laryngectomy in Chinese patients with laryngeal carcinoma. Health and Quality of Life Outcomes. 2019;17(1):132.

15. Bozec A, Schultz P, Gal J, et al. Evaluation of the information given to patients undergoing total pharyngolaryngectomy and quality of life: a prospective multicentric study. European Archives of Oto-Rhino-Laryngology. 2019;276(9):2531-2539.

16. Galli A, Giordano L, Biafora M, Tulli M, Di Santo D, Bussi M. Voice prosthesis rehabilitation after total laryngectomy: are satisfaction and quality of life maintained over time? ACTA Otorhinolaryngologica Italica. 2019;39(3):162-168.

17. Miyoshi M, Fukuhara T, Kataoka H, Hagino H. Relationship between quality of life instruments and phonatory function in tracheoesophageal speech with voice prosthesis. International Journal of Clinical Oncology. 2016;21(2):402-408.

18. Xi S. Effectiveness of voice rehabilitation on vocalisation in postlaryngectomy patients: a systematic review. International Journal of Evidence-Based Healthcare. 2010;8(4):256-258.

19. Endres L, Tit DM, Bungau S, et al. Markers usefulness in the melanic metastatic celular epitops identification in the sentinel lymph node. Rev Chim (Bucharest). 2018;69(12):3675-3679.

20. Terada T, Saeki N, Toh K, et al. Voice rehabilitation with Provox 2 voice prosthesis following total laryngectomy for laryngeal and hypopharyngeal carcinoma. Auris, Nasus, Larynx. 2007;34(1):65-71.

21. Filipovska-Mušanović $M$, Hodžić $D$, Hrnčić N, Hatibović H. Quality of life in patients with larygeal/hypopharyngeal cancer following total/partial laryngectomy. Medicinski Glasnik. 2012;9(2):287-292.

22. Bian X, Song T, Wu S. Outcomes of xerostomia-related quality of life for nasopharyngeal carcinoma treated by IMRT: based on the EORTC QLQ-C30 and H\&N35 questionnaires. Expert Review of Anticancer Therapy. 2015;15(1):109-119.

23. Bucur D, Berceanu D, Diaconu C. Hemostasis in patients with cirrhosis: a hazardous balance. Arch Balk Med Union. 2016;51(4):501-505.

24. Diaconu C. Atrial septal defect in an elderly woman - a case report. Journal of Medicine and Life. 2011;4(1):91-93.

25. Diaconu C, Nastasa A, Zaki AR, Arsalan M. Type 2 diabetes: a driver for chronic heart failure. The $2^{\text {nd }}$ International Conference on Interdisciplinary Management of Diabetes Mellitus and its Complications - Diabetes mellitus as cardiovascular disease, INTERDIAB 2016 Proceedings, pp. 201-210. Ed. Niculescu. Editors Serafinceanu C, Negoita O, Elian V. 